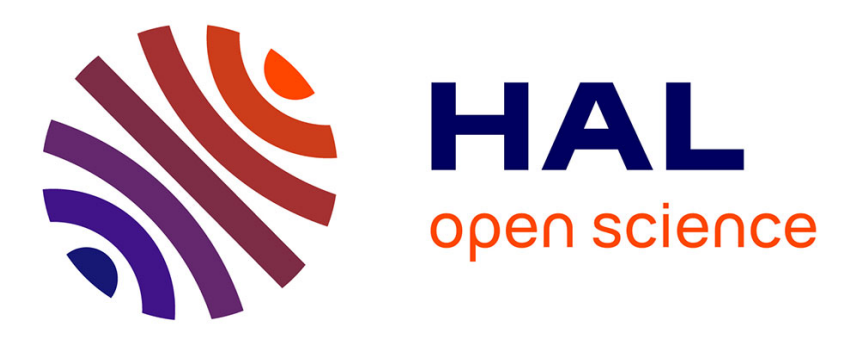

\title{
A Review on Conservation of Energy in Wireless Sensor Networks
}

\author{
Oluwadara J. Odeyinka, Opeyemi A. A Ajibola, Michael C. C Ndinechi, \\ Onyebuchi C. C Nosiri, Nnaemeka C. Chiemezie Onuekwusi
}

\section{To cite this version:}

Oluwadara J. Odeyinka, Opeyemi A. A Ajibola, Michael C. C Ndinechi, Onyebuchi C. C Nosiri, Nnaemeka C. Chiemezie Onuekwusi. A Review on Conservation of Energy in Wireless Sensor Networks. International Journal of Smart Sensor Technologies and Applications, 2020, 1 (2), pp.1. 10.4018/IJSSTA.20200401.oa1 . hal-03320134

\section{HAL Id: hal-03320134 \\ https://hal.science/hal-03320134}

Submitted on 14 Aug 2021

HAL is a multi-disciplinary open access archive for the deposit and dissemination of scientific research documents, whether they are published or not. The documents may come from teaching and research institutions in France or abroad, or from public or private research centers.
L'archive ouverte pluridisciplinaire HAL, est destinée au dépôt et à la diffusion de documents scientifiques de niveau recherche, publiés ou non, émanant des établissements d'enseignement et de recherche français ou étrangers, des laboratoires publics ou privés. 


\title{
A Review on Conservation of Energy in Wireless Sensor Networks
}

\author{
Oluwadara J. Odeyinka, Federal University of Technology, Owerri, Nigeria \\ Opeyemi A. Ajibola, University of Lagos, Nigeria \\ (iD) https://orcid.org/0000-0003-0353-8431 \\ Michael C. Ndinechi, Federal University of Technology, Owerri, Nigeria \\ Onyebuchi C. Nosiri, Federal University of Technology, Owerri, Nigeria \\ Nnaemeka Chiemezie Onuekwusi, Federal University of Technology, Owerri, Nigeria \\ iD https://orcid.org/0000-0001-8741-1686
}

\begin{abstract}
This paper is a review on energy conservation in wireless sensor networks (WSNs). Due to the nature of wireless sensor nodes in terms of deployment and their common usage in terrains with limited access, recharging or replacing sensor nodes batteries may be difficult. This paper examined various sources of energy in WSNs Battery, energy harvesting and energy transference. Also, various energy usage operations and energy wastage activities in WSNs were examined, and comparisons of different routing protocols based on network structure, energy dissipation, data communication cost, and entire energy usage in WSNs were itemized. The prospects of the machine learning (ML) approach in addressing energy constraint issues in WSNs were reviewed. This paper recommends a compound approach in routing decisions to maximize energy usage operation and minimize energy wastage activities, consideration for energy harvesting and transference mechanisms, and exploring the potentials in ML algorithms to resolve energy problem in wireless sensor networks.
\end{abstract}

\section{KEYWORDS}

Data Communication Cost, Energy Sources, Energy Usage Operations, Energy Wastage Activities, Machine Learning Algorithm, Network Structure

\section{INTRODUCTION}

Wireless Sensor Networks (WSNs) being a prominent technology in the field of communication engineering is envisioned to gain applications in many aspect of endeavor. Although, military applications such as battle field surveillance brought about the growth of WSNs, today, they are applied in industrial monitoring and control system, inventory management, border control, real time traffic control mechanism, disaster management and other applications. In most cases, wireless sensor nodes are set up in un-attended areas. In such circumstance, recharging or replacing wireless sensor nodes' battery may be difficult to moderate. Therefore, conserving sensor nodes' energy is a significant advancement objective.

Energy consumption operation of a WSN can be separated into the following: Sensing, Processing and Communication. Communication operation of a wireless sensor network consists of data 
transmission and reception. Among these operations, data transmission consumes most of the energy; approximately $80 \%$ (Anastasi et al., 2009). Normally, communication radio utilized in wireless sensor networks exist in two states; active and in-active state. During the active state, the radio operates in transmission and reception mode while the radio operates in sleep mode during in-active state. Zahra and Shima (2012) make it clear that data transmission forms the most power consumption mode in a WSN, while the power consumption in the idle mode is similar to that of the receiving mode. Power utilization in the sleep mode is the least compared to that of the idle listening. Conserving the energy of sensor nodes can extend the lifespan of a whole network (Kumar et al., 2017). Thus, making the deployment of wireless sensor nodes in viable areas to require stringent energy conservation plan.

There are basically three schemes proposed to save sensor battery such as: Duty cycle scheme which turns off the radio during periods of in-activity, data driven scheme and mobility scheme. Among the methods for energy savings, emphasis had been on data driven method through the utilization of data routing protocols to conserve sensor battery and the entire energy usage in wireless sensor networks. Therefore, energy related concerns which include battery usage of sensor nodes and maximization pose some technical challenges to WSNs and are of present receiving great research attention. Energy-conservation practices focus mainly on network and sensing sub-systems. In network sub-system, energy conservation is considered in the operations of each node and in the design of networking protocols. In sensing sub-system, methods are used to minimize the occurrence of energyexpensive samples. Data routing protocol being the most prominent method used to conserve energy in WSNs is mainly classified on the basis of network structure and protocol operations. There are three essential groups of routing protocols in WSNs based on the use of network structure to address energy issue (Chirihane et al., 2017). These includes: Flat routing protocol, Hierarchical (Clustering) routing protocol and Location based routing protocol. Subsequent classification is based on protocol operations such as: Negotiation based, Query based, Multipath based, Quality of Service (QoS) based and Coherent based.

The spotlight of this review on energy conservation in WSN are: Energy sources in WSNs, energy usage operations, energy wastage activities of sensor nodes, comparison of various network-based routing protocols considering energy usage performance parameter and review on the implementation of Machine Learning (ML) algorithms for energy efficiency in WSNs.

\section{ENERGY CONSERVATION IN WSNS}

The insatiable demand for energy, the unusual replacement of battery and the challenge of physical recharge of sensor's battery after deployment should necessitate the need for thorough plan for supply and management of energy in WSNs. Figure 1 is an energy architecture used as a structure for review carried out in this paper. The broad classification of energy conservation schemes in WSNs are: Duty cycle scheme, data driven method and mobility technique.

Duty cycle approach decides appropriate schedule to switch nodes OFF or ON for data communication. The essence of this is to reduce idle listening when a node unnecessarily pay attention to a channel thereby expending energy without data communication and overhearing when a node wait actively; resulting in possibility of receiving data destined to another node. The scheduling algorithm in duty cycle removes idle listening and overhearing because each node has its time window to access the wireless network.

Data driven method minimizes the transmission of redundant or duplicate data in a wireless sensor network. This method also put into consideration; energy-efficient data acquisition, data reduction techniques such as: In-network processing, data prediction and data compression to minimize the size of data being routed in a network (Hossam and Ahmad 2020). In ML algorithms for WSNs, data prediction technique is a prominent and viable option. Data prediction in WSNs is concerned with the building of a model for forecasting sensed parameters of sensor nodes using historical data (Raza et al., 2015; Engmann et al., 2020). The forecasted values are implemented when they fall within 
a pre-determined satisfactory threshold. In real time application, the prediction can be modeled on the Base Station (BS), Sensor nodes or on both. Data prediction approach is categorized into: Time series, Stochastic and Algorithmic approach. Time series models have been used to forecast future data values in WSNs (Engmann et al., 2020), typically to decrease the occurrence of data transmission. Typical examples of such Models are: Auto-Regressive Moving Average (ARMA), Auto-Regressive Integrated Moving Average (ARIMA), Least Mean Squares (LMS), and Grey Series.

Mobility-based technique is classified into; mobile sink and mobile relay. These ensured that the location of sensor nodes and Base Station is attuned to compensate for long distance transmission in a single hop data delivery method because nodes far from the Base Station (BS) expends additional energy for data transmission. Also, a trade-off of distance for energy in a multi-hop transmission is ensured to reduce transmission cost and the occurrence of energy hole (a situation where nodes closest to the sink depletes their energy earlier in a network). A new sink mobility algorithm developed by (Rahman et al., 2019) revealed that network duration could be enhanced through the operation of a sink node moving in accordance with the plans specified in the algorithm. As a result of the reduction of source range, power spending during data communication is reduced. Also, a Location-Aware Routing for Controlled Mobile Sinks (LARCMS) proposed by (Kumar and Kumar, 2019) help out in decreasing delay experienced during data reporting, enhanced network's lifespan, coordinate information about the position of the Sink and present a dependable power expenditure. Two portable Sinks were implemented for the compilation of data for a pre-defined route which proffer improved outcome.

\section{ENERGY SOURCES IN WIRELESS SENSOR NETWORKS}

The primary energy source to a node and the entire network of sensor nodes is the battery. Due to the reality that wireless sensor nodes are often deployed in an un-attended or restricted arena, in such a situation, the major operations of wireless sensor node; sensing, processing and communication are dependent on the battery to supply energy. However, there exists a possibility of harvesting energy from other sources to enhance sensor nodes' battery. The other sources of energy could be from solar energy and other renewable energy sources. Sensor nodes with a harvester antenna can obtain energy through Radio Frequency (RF) wave utilized in data communication. Also, mechanical and thermal sources such as: Vibration, wind, human body motion, thermal conductors and ambient temperature. Among these sources, energy supply through the battery is the most prominent and reliable source.

\section{ENERGY USAGE OPERATIONS IN WIRELESS SENSOR NETWORKS}

Sensor nodes usually utilize energy in its sensing, processing and communication operations. These operations need to be managed to diminish the usage of nodes energy to the minimum thereby extending the life-span of WSNs. The concerned operations are described as follows.

\section{Sensing}

Sensing operation in WSNs is when the desired event or parameter is being captured usually in form of analogue signal. A node is typically designed to suite a particular event or parameter proposed to be observed before deployment. Examples are: Acoustic sensors for detecting sound, pneumatic sensors for observing pressure, thermal sensors for monitoring temperature, magnetic sensors which may be applicable in real time traffic management system, industrial and oil exploration. The Analogueto-Digital Converter (ADC) embedded in the sensing sub-unit of a wireless sensor node converts analogue signal to digital signal. Therefore, in sensing, energy utilization is due to data sampling and analogue to digital conversion. 
Figure 1. Energy Architecture in WSNs

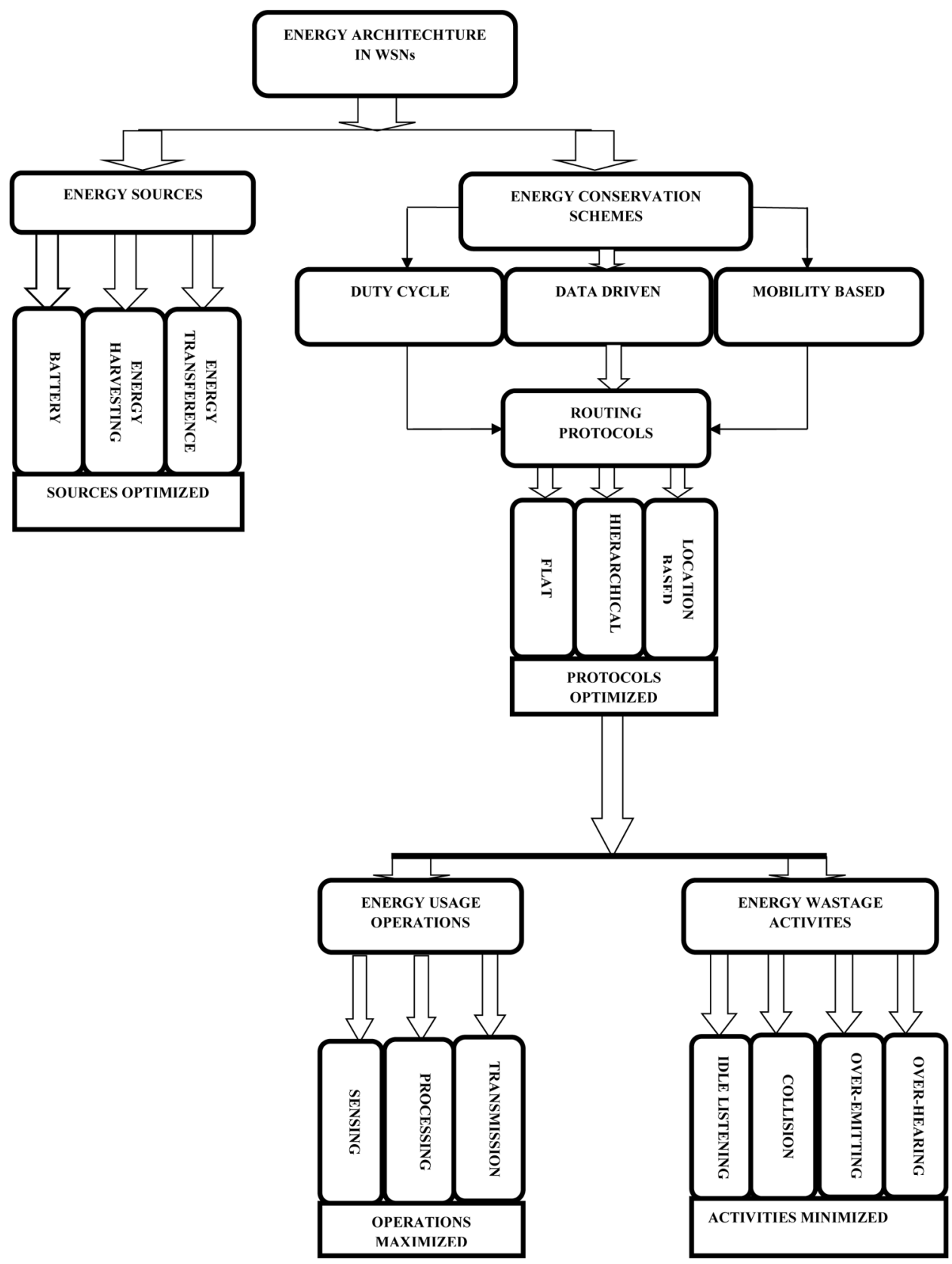

\section{Processing}

Data processing operation in WSNs entails; sensor controlling, data compression, data fusion and aggregation which enhances reduction in the size of data to be transmitted, thereby reduces the cost of data transmission. Data processing operation also helps to remove redundant and duplicate data in a network. One important parameter to consider in processing operation of a sensor node and the entire operations of node in a network is the processing duration (time). In an ideal electronic/sensor 
circuit, the basic energy demand $\left(\mathrm{E}_{\text {elect }}\right)$ is the measure in Joules or Watt-seconds of the product of Current $\mathrm{I}_{\text {elect }}$ (Ampere) flowing through the circuit and Voltage $\mathrm{V}_{\text {elect }}$ (Volts) across the terminal of the circuit, utilized in a unit Time ' $\mathrm{T}$ ' (seconds). Therefore:

$$
E_{\text {elect }}=I_{\text {elect }} \times V_{\text {elect }} \times T
$$

The parameter; $I_{\text {elect }} \times V_{\text {elect }}$ defines nodes' circuits power, $P_{\text {elect }}$ in Watts of transmitter, receiver and or the amplifier circuit and $\mathrm{T}$ is the time taken to complete a task. Therefore:

$$
E_{\text {elect }}=P_{\text {elect }} \times T
$$

For time $\mathrm{T}=1$ seconds, 2 seconds, 3 seconds ..., $\mathrm{N}$ seconds:

For time $T=1$ seconds, $E_{\text {elect }}=P_{\text {elect }}$

For time $T=2$ seconds, $E_{\text {elect }}=P_{\text {elect }} \times 2$

For time $T=3$ seconds, $E_{\text {elect }}=P_{\text {elect }} \times 3$

Thus, for time $\mathrm{T}=\mathrm{N}$ seconds, $E_{\text {elect }}=P_{\text {elect }} \times N$

Based on the fact that the energy consumed by sensor nodes to execute various operations in a network is directly proportional to the time taken to accomplish a task, it is necessary to design a strategy for speedy execution of tasks such as: Data processing, switching period between modes; (Sleep, idle and active) and other operations.

\section{Communication}

Data communication in WSNs involves transmission of processed data from the transmitting node and reception of data at the receiving node. The communication sub-unit of a wireless sensor node consists of a transceiver that is capable of transmitting and receiving data and the radio module usually a zig-bee which enhances the connectivity between nodes. The amount of energy in utilizing the radio for the transmission of data is always greater than the energy expenditure during reception due to the fact that data has to be transmitted over a certain distance to reach the receiving node. The total cost of data communication in WSNs is the sum of transmission cost and reception cost. Table 1 listed out transmission and reception parameters basically used to estimate the cost of data transmission, reception and communication of a ' $\mathbf{n}$ ' bit data along a distance ' $\mathbf{d}$ ' in the respective equations. NA means Not Applicable.

Fundamentally, the energy requirement of a sensor node to transmit a ' $\mathbf{n}$ ' bit of data is proportional to the square of the distance ' $\mathbf{d}$ ' between the transmitting end and the destination while the operating power of the transmitter circuit and amplifier is constant. However, when ' $\mathbf{d}$ ' is equivalent to or 
Table 1. List of Transmission and Reception Parameters

\begin{tabular}{|l|l|l|}
\hline \multicolumn{1}{|c|}{ Parameter Description } & \multicolumn{1}{|c|}{ Transmission Symbol } & \multicolumn{1}{c|}{ Reception Symbol } \\
\hline $\begin{array}{l}\text { Energy Requirement of Transceiver } \\
\text { Circuits }\end{array}$ & $\begin{array}{l}\mathrm{E}_{\mathrm{Tx}} \text { : Energy required by transmitter } \\
\text { circuits }\end{array}$ & $\mathrm{E}_{\mathrm{Rx}}$ : Energy required by receiver circuits \\
\hline $\begin{array}{l}\text { Size of the data packet in bits; } \\
\text { assuming no data loss }\end{array}$ & n: Size of data to be transmitted & n: Size of data to be received \\
\hline $\begin{array}{l}\text { Energy requirement of transmitter } \\
\text { amplifier }\end{array}$ & $\begin{array}{l}\epsilon_{\text {amp }}: \text { Free space transmitter } \\
\text { amplifier energy }\end{array}$ & NA \\
\hline $\begin{array}{l}\text { Communication Distance } \\
\text { d: Distance from transmitting node } \\
\text { to receiving node }\end{array}$ & NA \\
\hline $\begin{array}{l}\text { Pre-defined threshold value } \\
\text { of distance for a particular } \\
\text { environment }\end{array}$ & $\begin{array}{l}\mathrm{d}_{0}: \text { Maximum expected transmission } \\
\text { mintance for free space channel with } \\
\text { minum obstruction }\end{array}$ & NA \\
\hline
\end{tabular}

exceeds a pre-defined threshold $\mathbf{d}_{\mathbf{0}}$, the fourth power of ' $\mathbf{d}^{\prime}$ '; $\left(\mathrm{d}^{4}\right)$ is utilized to estimate transmission and communication cost:

Transmission cost: $E_{T}(n, d)=n\left(E_{T X}+d^{2 *} \in_{a m p}\right)$

Reception cost: $E_{R}(n)=n\left(E_{R X}\right)$

Communication cost: $E=E_{T}+E_{R}=n\left(E_{T X}+d^{2} * \epsilon_{a m p}+E_{R X}\right)$

To determine the optimal energy path for communication, it is essential to put into consideration the shortest route from source node to BS and the energy content of sensor nodes along the desired route. Equations 7, 8 and 9 are valid for one hop communication from source to BS. However, for multi-hop communication where data is transmitted over a certain number $\left(\mathrm{n}_{0}\right)$ of hops with a minimum distance $\left(\mathrm{d}_{\mathrm{m}}\right)$ between nodes, distance ' $\mathbf{d}$ ' is therefore given as:

$d=n_{0} * d_{m}$

Let the quantity $n_{0} * d_{m}=x$ in equation 10 :

$d=x$

Substituting equation 11 in 7 :

$E_{T}(n, x)=n\left(E_{T X}+x^{2 *} \in_{a m p}\right)$ 
Similarly, for data transmitted in multi-hop, it requires $n_{0}-1$ times reception at the nodes before reaching the BS. Thus, total reception cost of ' $n$ ' bit data in a multi-hop is:

$E_{R}(n)=n_{0}-1\left(n * E_{R X}\right)$

and the total communication cost is expressed in equation 14 as:

$E=n\left[E_{T X}+x^{2 *} \in_{a m p}+n_{0}-1\left(E_{R X}\right)\right]$

Thus, the product of $\mathrm{n}_{0}$ and $\mathrm{d}_{\mathrm{m}}$ parameters in the transmission and communication cost equations reduces the transmitting distance, enhances balanced usage of energy and consequently reduces communication cost in a multi-hop routing. However, the major task of communication protocols is not only to locate the least energy route from a source node to BS, but also find the most resourceful method to extend network duration and this is envisioned to be effectively accomplished with the implementation of ML algorithms.

\section{ENERGY WASTAGE ACTIVITIES IN WSNS}

The common energy wastage activities in WSNs are: Idle listening; a scenario where a node listens to an idle channel so as to receive possible traffic (Sahoo et al., 2014). Collision; a situation whereby a node receives more than a packet concurrently and leading to re-transmission of excess packet and energy wastage (Tao et al., 2012). Over-emitting; when data is transmitted by a node unexpectedly. Over-hearing; describes what happens when a node take delivery of data destined to another node (Zahra and Shima, 2012; Hossam and Ahmad, 2020).

Majority of the current energy minimization models neglects other parameters for energy conservation and focused on data transfer and reception. The power consumption modeled by (Heinzelman et al., 2000) and (Heinzelman et al., 2002) focused on the cost of data transfer and reception and figured out the upper limit for energy-efficiency of one hop distance. The method considered a midway node between the sending end and the receiving end so that the re-transmission will save energy. Junaid et al., (2014) emphasized that in the design of an energy-efficient algorithm, consideration for energy supply and energy consumption in parallel is very paramount. Energy savings in WSNs therefore requires a good conservation plan which should be able to examine energy sources, energy usage operations and energy wastage activities.

\section{ROUTING PROTOCOLS IN WSNS}

In wireless sensor networks, routing protocol is defined as the manner of data dissemination from the network field to the BS or resource management center (Manap et al., 2013). However, data routing technique has become a complex issue due to the following factors: Dynamic nature of WSNs, inadequate battery life, computational overhead, self-organization and restricted range of sensor nodes. Consequent to the inadequate battery life and the fact that battery replacement is sometimes difficult to realize due to the area of deployment, the network lifetime is limited. Therefore, a careful management of energy resources is required to increase the lifespan of wireless sensor networks. WSNs routing protocols discover and maintain energy-efficient paths for reliable and efficient communication in a network (Al-karaki and Kamal, 2004). The major purpose of the design of routing procedure (protocol) is to elongate the lifetime of a network by ensuring the sensors are kept active for a long period because of limitations in the energy of sensor nodes. Therefore, to maintain 
longer connectivity of a network, the design of routing protocols that accommodates the transaction between energy spending and optimization is very necessary. Generally, routing protocols in WSN are classified on the basis of network structure and the operation of protocols.

\section{CLASSIFICATION OF ROUTING PROTOCOLS BASED ON NETWORK STRUCTURE}

The structure of the network plays vital role in the operation of the routing protocols in wireless sensor networks. The three major classes of routing protocols based on network structure are: Flat, hierarchical and location based routing protocol. Table 2 compares some of the routing protocols.

\section{Flat Routing Protocol}

In flat routing protocol, each node plays the same role and nodes work together to perform the sensing task (Al-karaki and Kamal, 2004), (Jian-guang et al., 2010). Flat routing protocols are operative in WSNs that are small in size and are fairly undesirable in large scale deployment due to resource limitations. Data transmission is performed hop by hop, usually using the form of flooding (Liu, 2012). Flooding, Gossiping, SPIN (Sensor Protocol for Information via Negotiation) and Directed Diffusion are some of the routing protocols that utilized flat network structure. In Flooding, a given node transmits data to its neighbours which in turn transfer same data to their entire neighbour for all nodes to be reached. In Gossiping, data is only transmitted to one neighbor that is selected at random. Gossiping conserves more energy than Flooding. In SPIN, before data transmission, nodes negotiate with each other so that it will overcome collapse and overlap of nodes. A routing protocol in WSNs where the Base Station generates interest that diffuse through the network is called Directed Diffusion. It is an application aware protocol. The intermediate nodes for matching data in a specific direction are searched using Gradients. Proper selection of the good path makes for energy conservation in diffusion, which enables local multipath interaction, thus improves usage of bandwidth.

\section{Location Based Routing Protocol}

In location based routing protocol, the location information of wireless networks is utilized in routing data in an energy-efficient manner. Global Positioning System (GPS) devices are attached to each sensor node for accurate localization. This location information is used to calculate the distance between two given nodes for proper estimate of energy utilization. The awareness of the region to be sensed by nodes enhances the diffusion of query to that specific region thereby limiting the number of transmission in the out-of-region space. The location-based routing is ideal for mobile ad hoc networks. Summarily, location-based routing requires three facts:

- Each node in the network must know the information of its own location (Niculescu 2004);

- Each node must be conscious of the position of its adjacent nodes; one-hop away from it;

- The destination node's location must be known to the source.

\section{Hierarchical Routing Protocol}

Hierarchical routing protocol is a cluster-based routing. It was initially proposed in wire line networks. It is a two-layer protocol that utilizes one layer for cluster heads selection and the other layer for routing. It is a popular technique which is scalable and provides efficient nodes communication. This protocol is employed to perform energy-efficient routing in WSNs. In hierarchical routing, nodes perform dissimilar function and are usually arranged into clusters based on definite requirements. Formation of clusters and assignment of specific duty to Cluster Head $(\mathrm{CH})$ can extensively contribute to energy efficiency and lifetime extension of a network. While higher energy nodes are responsible for information processing and transmission, sensor nodes with low energy content can perform data 
sensing in a hierarchical architecture. Thus, hierarchical routing protocol efficiently reduces intracluster energy consumption, performs data aggregation and fusion so as to lower the size of data that is transmitted to the Base Station (BS). Though, the first hierarchical routing protocol proposed by Heinzelman et al., (2000) had limitations such as: One hop data routing technique through the $\mathrm{CH}$ and non consideration for nodes residual energy. Subsequent routing protocols under the hierarchical category addressed the limitations.

Table 2 shows that hierarchical routing protocol performs best in addressing energy wastage activities, energy usage operation and communication cost in wireless sensor networks.

\section{CLASSIFICATION OF ROUTING TECHNIQUES BASED ON PROTOCOL OPERATION}

Based on protocol operation, routing technique in WSNs is classified as: Negotiation based, Query based, Multipath based, Quality of Service (QoS) based and Coherent based (Al-karaki and Kamal, 2004). The protocols under this taxonomy operate on the basis of network-structure operation or the manner the structure needs the protocols to function depending upon sudden changes in the network. Protocols are further classified as proactive, reactive and hybrid based on the type of communication routes processed in a network for data communication from source to destination.

\section{Multi Path-Based}

These protocols are competent in managing multiple paths. Sensor nodes send the received data on multiple paths rather than passing through a single path thereby reducing the energy budget for each path in a network.

\section{Query-Based}

Query-based routing broadcast the use of queries issued by the Base Station requesting for certain information from the nodes in the network. A sensor node accountable for data sensing and collection reads these queries and search for a match with the requested data in the queries. Once there is a match, it starts data transfer process to the appropriate node or Base Station. This process is well-known as Directed Diffusion. These queries, which move in the network, generate a path while passing through all the nodes. In this method, less energy is used and data aggregation is executed on a route. Thus, Query based protocol operation achieves energy efficiency by increasing the quantity of information obtained with low latency and low bandwidth through the instrument of high level queries.

\section{Negotiation-Based}

These protocols make use of complex descriptors coded in high level in order to get rid of redundant data in transmission. Due to the fact that flooding is used to disseminate data, resulting in data collision, nodes thereby receive duplicate data during transmission. Thus, a repeated negotiation is carried out to remove duplicate data through continuous exchange of the same set of data between the same set of nodes. This operation aimed to achieve energy efficiency by removing redundant data and reducing the size of data before transmission. However, the repeated negotiation consumes a lot of energy.

\section{Quality of Service (QoS) Based}

In this operation, service quality and energy are maintained in the network. Whenever the BS requests for data from the sensed nodes in the network, the transmission has to suit definite Quality of Service consideration such as: Bounded latency (sensed data must be sent without delay) and Bandwidth consumed. 
Table 2. Comparison of Various Routing Protocols Based on Network Structure

\begin{tabular}{|c|c|c|c|c|c|}
\hline Routing protocol & Classification & $\begin{array}{c}\text { Data } \\
\text { Aggregation }\end{array}$ & $\begin{array}{l}\text { Energy } \\
\text { wastage }\end{array}$ & $\begin{array}{l}\text { Energy } \\
\text { usage }\end{array}$ & $\begin{array}{c}\text { Communication } \\
\text { cost }\end{array}$ \\
\hline $\begin{array}{l}\text { Sensor Protocol for Information } \\
\text { via Negotiation (SPIN) }\end{array}$ & Flat & Yes & High & Low & High \\
\hline Directed Diffusion & Flat & Yes & High & Low & High \\
\hline Rumour Routing & Flat & Yes & NA & NA & NA \\
\hline Acquire & Flat & Yes & NA & NA & NA \\
\hline Cougar & Flat & Yes & High & Low & High \\
\hline Energy Aware Routing (EAR) & Flat & No & NA & NA & NA \\
\hline $\begin{array}{l}\text { Minimum Cost Forwarding } \\
\text { Algorithm (MCFA) }\end{array}$ & Flat & No & NA & NA & NA \\
\hline Gradient Based Routing (GBR) & Flat & Yes & NA & NA & NA \\
\hline $\begin{array}{l}\text { Geographic Adaptive Fidelity } \\
\text { (GAF) }\end{array}$ & Location-based & No & High & Low & High \\
\hline $\begin{array}{l}\text { Geographic and Energy Aware } \\
\text { Routing (GEAR) }\end{array}$ & Location-based & No & High & Low & High \\
\hline $\begin{array}{l}\text { Greedy other Adaptive Face } \\
\text { Routing (GOAFR) }\end{array}$ & Location-based & No & NA & NA & NA \\
\hline $\begin{array}{l}\text { Most Forward within Radius } \\
\text { (MFR) }\end{array}$ & Location-based & No & NA & NA & NA \\
\hline $\begin{array}{l}\text { Geographic Distance Routing } \\
\text { (GEDIR) }\end{array}$ & Location-based & No & NA & NA & NA \\
\hline $\begin{array}{l}\text { Low Energy Adaptive } \\
\text { Clustering Hierarchy (LEACH) }\end{array}$ & Hierarchical & Yes & Low & High & Low \\
\hline $\begin{array}{l}\text { Improved Energy Efficient } \\
\text { LEACH (IEE-LEACH) }\end{array}$ & Hierarchical & Yes & Low & High & Very Low \\
\hline $\begin{array}{l}\text { Threshold-Sensitive Energy } \\
\text { Efficient Sensor Network } \\
\text { (TEEN) }\end{array}$ & Hierarchical & Yes & Low & High & Low \\
\hline $\begin{array}{l}\text { Adaptive Threshold TEEN } \\
\text { (APTEEN) }\end{array}$ & Hierarchical & Yes & Low & High & Low \\
\hline $\begin{array}{l}\text { Power Efficient Gathering in } \\
\text { Sensor Information System } \\
\text { (PEGASIS) }\end{array}$ & Hierarchical & No & Low & High & Low \\
\hline $\begin{array}{l}\text { Minimal Energy } \\
\text { Communication Network } \\
(\mathrm{MECN})\end{array}$ & Hierarchical & No & Low & High & Low \\
\hline $\begin{array}{l}\text { Small Minimal Energy } \\
\text { Communication Network } \\
(\mathrm{SMECN})\end{array}$ & Hierarchical & No & Low & High & Low \\
\hline $\begin{array}{l}\text { Virtual Grid Architecture } \\
\text { (VGA) }\end{array}$ & Hierarchical & Yes & NA & NA & NA \\
\hline $\begin{array}{l}\text { Standard Operating Procedures } \\
\text { (SOP) }\end{array}$ & Hierarchical & No & NA & NA & NA \\
\hline $\begin{array}{l}\text { Hierarchical Partition-Based } \\
\text { Anonymous Routing (HPAR) }\end{array}$ & Hierarchical & No & NA & NA & NA \\
\hline
\end{tabular}

Sources: Some contents within Table 2 are extracted from Misra, et al. (2009) and Goncalves, et al. (2019) 


\section{Coherent-Based}

In this operation, the sensor nodes in the network collect data and perform a minimal process such as duplicate suppression and time stamping on the data before it is forwarded to the aggregators (nearest neighbors or BS) for further processing. The technique is energy efficient and reduces delay.

\section{MACHINE LEARNING RELATED; ENERGY EFFICIENT ROUTING PROTOCOLS IN WSNS}

Ho et al. (2012) developed a ladder diffusion algorithm to resolve the constraint of energy expenditure in routing, making use of Ant Colony Optimization (ACO) technique which decides transmit lanes and efficiently trims down energy expenditure. Ailian et al. (2018) combined the merits of the Ant Colony Optimization algorithm and minimum hop routing strategy to successfully decrease energy utilization in the network considered. Bhushan and Sahoo (2020) proposed a Fuzzy based clustering technique known as 'Intelligent and Secured Fuzzy Clustering Algorithm using Balanced Load Sub Cluster Formation' (ISFC-BLS) which facilitates cooperative communication in the network. The balanced load sub-cluster formation discovers nodes which joins the cluster. ACO technique was implemented to locate the optimal route to the destination. By reducing the number of control messages and energy consumption of sensor nodes, the protocol achieved a secured and effective clustering technique compared to other technique for improving network lifespan and enhancing energy efficiency. The Equilibrium Strategy-Based Routing Optimization Algorithm (ESRA) for WSNs projected by (Tang et al., 2018) initially put up a minimum energy spending tree and thereafter offers a cut-edge approach to achieve load stability between nodes. The approach efficiently makes use of energy and lengthens the network existence. Samara and Aljaidi (2018) proposed a Best First Search (BSF) Artificial Intelligence (AI) Algorithm. The method was used in selecting a next-hop data communication route. The authors aimed to maximize the duration of the network, enhance system reliability and the average delivery rate of information using a multi-variable heuristic function. Samara and Aljaidi (2019) introduced an Artificial Intelligent algorithm which route data efficiently in the network with minimal consumption of energy. Two protocols based on K-Nearest Neighbour (KNN) and Artificial Neural Network (ANN) ML algorithms were developed to achieve better performance in WSNs. A protocol was proposed by (Gental and Lobiyal, 2019) on the basis of Genetic Algorithms for energy-aware multipath routing techniques. The protocol introduced a cost function that considers the distance between the centre and the event arena, the center and Base Station together with nodes' residual energy for Cluster Head selection. The protocol enhances energy efficiency.

In WSNs, there are other issues that causes energy wastage. It is possible for a sensor in a network to develop fault due to deployment or some environmental situations, which can cause congestion, loss of data, transmissions failure, re-routing problem, extension of transmission path, thereby resulting to extra use of energy. Similarly, event detection, target tracking and localization (recognizing the geographic location of sensor nodes) if not properly managed, can cause a network to consume more than the budgeted power. Therefore, state-of-the-art algorithms in Machine Learning can improve the performance of WSNs and maintain an acceptable equilibrium in energy consumption. Table 3 presents few notable ML algorithms and their applications in WSNs.

Due to the challenges associated with traditional routing protocols in WSNs and future projection of large scale deployment of sensor nodes in a dynamic environment, it is important to direct research towards the implementation of ML algorithm such as: Fuzzy Logic, decision tree, reinforcement learning and neural networks which are able to provide facilities to extend network duration, learn the properties of a dynamic environment and effectively utilize the varying nature of WSNs. 
Table 3. Notable ML Algorithms Applicable in WSNs

\begin{tabular}{|c|c|c|}
\hline ML Algorithms & Category of Learning & Applications in WSNs \\
\hline Regression & Supervised & $\begin{array}{l}\text { Localization, connectivity challenges, data } \\
\text { aggregation and energy harvesting }\end{array}$ \\
\hline Decision Tree & Supervised & $\begin{array}{l}\text { Fault detection, data aggregation and } \\
\text { selection of path for mobile Sink }\end{array}$ \\
\hline Artificial Neural Networks (ANN) & Supervised & $\begin{array}{l}\text { Localization, data aggregation and } \\
\text { routing, fault detection and congestion } \\
\text { control }\end{array}$ \\
\hline Deep Learning & Supervised & $\begin{array}{l}\text { Data routing, data quality evaluation, fault } \\
\text { detection and energy harvesting }\end{array}$ \\
\hline Support Vector Machine (SVM) & Supervised & $\begin{array}{l}\text { Localization, data routing, connectivity } \\
\text { problem, fault detection and congestion } \\
\text { control }\end{array}$ \\
\hline Bayesian & $\begin{array}{l}\text { Supervised (Statistical } \\
\text { Based) }\end{array}$ & $\begin{array}{l}\text { Localization, fault detection, coverage } \\
\text { issues, event detection, target tracking and } \\
\text { mobile sink route selection }\end{array}$ \\
\hline K- Nearest Neighbour (KNN) & Supervised & Data aggregation and fault detection \\
\hline K-Means Clustering & Unsupervised & $\begin{array}{l}\text { Selecting the best } \mathrm{CH} \text { for routing and for } \\
\text { finding mobile Sink pathway }\end{array}$ \\
\hline Fuzzy-C-Means Clustering & Unsupervised & $\begin{array}{l}\text { Localization, connectivity and mobile } \\
\text { sink route selection }\end{array}$ \\
\hline Singular Value Decomposition (SVD) & Unsupervised & Data aggregation and routing \\
\hline Principle Components Analysis (PCA) & Unsupervised & $\begin{array}{l}\text { Localization, data aggregation, target } \\
\text { tracking and fault detection }\end{array}$ \\
\hline Evolutionary Computation & Reinforcement & $\begin{array}{l}\text { Localization, coverage issues, routing of } \\
\text { data, target tracing and mobility of Sink. }\end{array}$ \\
\hline
\end{tabular}

\section{CONCLUSION}

Energy consumption in WSNs is such that nodes expend energy to sense, process, transmit and receive viable data and at other occasion, nodes dissipate energy to execute wasteful activities, operate on nonviable data and transmit duplicate data. Hence, energy saving is one of the solutions to the resourceful operation of WSNs. Some long-established methods generally decreases the communication distance and energy expenditure of data transmission lane, consequently, extending the duration of a wireless sensor network. However, it is reasonable to consider multi-routing information and implement a compound approach in routing choice, and it is as well essential to expansively consider an assortment of nodes and network attributes for ML based data routing technique in Wireless Sensor Networks. Similarly, for utmost energy conservation, the deployment of networks of sensor node should be able to consider reliable energy sources, minimize wastage activities, maximize useful operations of sensor nodes and optimize the routing protocols.

\section{RECOMMENDATIONS}

The following recommendations are made to alleviate energy constraint issue in WSNs and offer direction for further studies: 
1. More research attention should be directed towards the factors that enhances energy wastage activities in WSNs.

2. Experimental research should also be surveyed into hybrid of different classifications of routing protocols.

3. Future design and fabrication of wireless sensor nodes should put into consideration energy harvesting and transference mechanisms with little or no compromise on sensor size.

4. More research work is recommended in the use of Machine Learning Algorithms to coordinate energy usage operations in WSNs. 


\section{REFERENCES}

Ailian, J., \& Lihong, Z. (2018). An Effective Hybrid Routing Algorithm in WSN: Ant Colony Optimization in combination with Hop Count Minimization. Sensors (Basel), 18(4), 1020. doi:10.3390/s18041020 PMID:29596336

Al-karaki, J. N., \& Kamal, A. E. (2004). Routing Techniques in Wireless Sensor Networks: A Survey. IEEE Wireless Communications, 11(6), 6-28. doi:10.1109/MWC.2004.1368893

Anastasi, G., Conti, M., Di Francesco, M., \& Passarella, A. (2009). Energy conservation in wireless sensor networks: A survey. Ad Hoc Networks, 7(3), 537-568. doi:10.1016/j.adhoc.2008.06.003

Bhushan, B., \& Sahoo, G. (2020). Intelligent and Secured Fuzzy Clustering Algorithm Using Balanced Load SubCluster Formation in WSN Environment. Wireless Personal Communication, 111. 10.1007/s11277-019-06948-0

Chirihane, G., Zibouda, A., \& Mohamed, B. (2017). A survey on clustering routing protocols in wireless sensor networks. Sensor Review.

Engmann, F., Apietu Katsriku, F., Abdulai, J., \& Adu-Manu, K. (2020). Reducing the Energy Budget in WSN Using Time Series Models. Wireless Communications and Mobile Computing, 2020, 1-15. Advance online publication. doi:10.1155/2020/8893064

Genta, D., \& Lobiyal, J. A. (2019). Energy Efficient Multipath Routing Algorithm for Wireless Multimedia Sensor Network. mdpi.com.

Goncalves, F., Ribeiro, B., Gama, O., Santos, A., Costa, A., Dias, B., Macedo, J., \& Nicolau, M. J. (2019). A Systematic Review on Intelligent Intrution Detection Systems for VANETs. 11th International Congress on Ultra-Modern Telecommunications and Control Systems and Workshops (ICUMT).

Heinzelman, W. B., Chandrakasan, A., \& Balakrishan, H. (2000). Energy-efficient Communication protocol for wireless micro-sensor Networks. Proceeding of the 33rd Hawaii International conference on System sciences, $1-10$.

Heinzelman, W. B., Chandrakasan, A., \& Balakrishan, H. (2002). An application specific protocol architecture for wireless micro sensor networks. IEEE Transactions on Wireless Communications, 1(4), 660-670. doi:10.1109/ TWC.2002.804190

Ho, J., Shih, H., Liao, B., \& Chu, S. (2012). A ladder diffusion algorithm using ant colony optimization for wireless sensor networks. Inf. Sci, 192, 204-212. doi:10.1016/j.ins.2011.03.013

Hossam, M., \& Ahmad, F. (2020). Wireless Sensor Networks. Springer Science and Business Media LLC.

Jian-guang, J., Zun-wen, H., Jing-ming, K., \& Yuhang, M. (2010). An Energy Consumption Balanced Clustering Algorithm for Wireless Sensor Network. International Conference on Computational Intelligence and Software Engineering.

Junaid, A. K., Hassaan, K. Q., \& Adnan, I. (2014). Energy management in Wireless Sensor Networks: A survey. Computers and Electrical Engineering, Elsevier., 41, 159-176. doi:10.1016/j.compeleceng.2014.06.009.hal01283728

Kumar, A., Shwe, H. U., Wong, K. J., \& Chong, P. H. J. (2017). Location-Based Routing Protocols for Wireless Sensor Networks: A Survey. Wireless Sensor Network, 9(01), 25-72. doi:10.4236/wsn.2017.91003

Kumar, V., \& Kumar, A. (2019). Improving reporting delay and lifetime of a WSN using controlled mobile sinks. Journal of Ambient Intelligence and Humanized Computing, 10(4), 1433-1441. doi:10.1007/s12652-018-0901-5

Liu, X. X. (2012). A survey on clustering Routing protocols in wireless sensor networks. Sensor. https://dol. org/ $10.3390 / \mathrm{s} 120811113$

Manap, Z., Mohd Ali, B., Kyun-Ng, C., Noordin, N. K., \& Sali, A. (2013). A Review on Heirarchical Routing Protocols for Wireless Sensor Networks. Wireless Personal Communications, 72(2), 1077-1104. doi:10.1007/ s11277-013-1056-5

Misra, S., Woungang, I., \& Misra, S.C. (2009). Guide to Wireless Sensor Networks. Springer Science \& Business Media 2009. 
Niculescu, D. (2004). Positioning in Ad Hoc Sensor Networks. IEEE Network, 18(4), 24-29. doi:10.1109/ MNET.2004.1316758

Rahman, H., Rehena, Z. \& Mukherjee, N. (2019). Sink Mobility To Ensure Coverage in Multi-Partitioned Wireless Sensor Network. Academic Press.

Raza, U., Camerra, A., Murphy, A. L., Palpanas, T., \& Picco, G. P. (2015). Practical data prediction for realworld wireless sensor networks. IEEE Transactions on Knowledge and Data Engineering, 27(8), 2231-2244. doi:10.1109/TKDE.2015.2411594

Sahoo, B. P. S., Puthal, D., \& Rath, S. (2014). An Energy Efficient Optimal Routing Method for Wireless Sensor Network. Journal of Science and Technology, 4(10), 558-564. https://www.worldcat.org/issn/2225-7217

Samara, G., \& Aljaidi, M. (2018). Aware-routing protocol using best first search algorithm in wireless sensor. iajit.org.

Samara, G., \& Aljaidi, M. (2019). Efficient energy, cost reduction and QoS based routing protocol for wireless sensor networks. Academic Press.

Tang, L., Lu, Z., Cai, J., \& Yan, J. (2018). An Equilibrium Strategy-Based Routing Optimization Algorithm for Wireless Sensor Networks. Sensors (Basel), 18(10), 3477. doi:10.3390/s18103477 PMID:30332753

Tao, Y., Elis, K., Tetsuya, O., Leonard, B., Muhammad, Y., \& Makoto, T. (2012). Performance Evaluation of WSNs Considering MAC and Routing Protocols Using Good put and Delay Metrics. 15th International Conference on Network-Based Information Systems.

Zahra, R., \& Shima, M. (2012). Energy saving in wireless sensor networks. International Journal of Computer Science and Engineering Survey, 3(1), 24. 
Oluwadara J. Odeyinka obtained B.Tech degree in Electronic and Electrical Engineering from Ladoke Akintola University of Technology (LAUTECH) Ogbomoso, Nigeria and M.Eng in Electrical and Electronic Engineering (Communication Engineering Option) from Federal University of Technology (FUT) Owerri, Nigeria. His research interests are in areas of Wireless Sensor Networks, Microwave Communications and Machine Learning.

Opeyemi A. Ajibola received BTech (Hons) in Electronic and Electrical Engineering from Ladoke Akintola University of Technology, Ogbomoso, Nigeria in 2011 and MSc in Electrical and Electronic Engineering with specialization in Communication Engineering from University of Lagos, Nigeria in 2016 respectively. He is currently the acting $H O D$, Department of Electrical and Telecommunication Engineering, ESGT - Benin University, Republic of Benin. His research interest is in the area of Wireless Communication, Digital Signal Processing and Machine Learning.

Michael C. Ndinechi was the formal Director, ICT Center and he is currently the Dean, School of Electrical System Engineering Technology, Federal University of Technology, (FUT) Owerri, Nigeria. He has served as Head of Department of Electrical and Electronic Engineering (2015 to 2016) and Associate Dean of the School of Engineering and Engineering Technology FUT, Owerri (2008 to 2010). He was the Director/CEO of the Electronics Development Institute, ELDI, Awka, Federal Ministry of Science and Technology, Nigeria from 2010 to 2014. He obtained his PhD degree in 2008 and specialized in Electrical and Electronics Engineering. In 1995, he obtained the University of Greenwich, London postgraduate certificate in Data Communications. He is registered with the Council for the Regulation of Engineering in Nigeria (COREN), a Corporate Member of Nigerian Society of Engineers, and a Member of Nigerian Institute of Management. Prof. Ndinechi has received many awards which include Federal Government of Nigeria Postgraduate Scholarship Award 1990, World Bank/National Universities Commission (Nigeria) Research Fellowship Award, 1994, Africa Educational Trust Award, London, 1995, National Award for Industrial and Business Development (NAIBD), Distinguished Leadership in National Development Gold Award (D'LINGA 2012) etc. His research interest is on Algorithms for Energy Conservation in Digital Systems, Modeling and Simulation of Wireless Sensor Networks using loT.

Nosiri Onyebuchi Chikezie is a Senior Lecturer, at the department of Electrical and Electronic Engineering, Federal University of Technology, Owerri. He has to his credit, the following qualifications: B. Eng in Electrical and Electronic Engineering, M.Eng and PhD in Electronic and Computer Engineering (Telecommunication Option). He is a research scholar in Wireless and data communication, wireless sensor networks. He has devoted much enthusiasm for developing new strategies in solving various wireless network challenges faced by Nigerian Network operators. He is an active member of the following professional bodies: Nigerian Society of Engineers (NSE), Council for the Regulation of Engineering (COREN) and Institute of Electrical and Electronic Engineering (IEEE).

Nnaemeka Chiemezie Onuekwusi is a lecturer at the Department of Electrical and Electronic Engineering of the Federal University of Technology Owerri, Imo State, Nigeria. From the same institution, he received his Bachelor's Degree in Electrical and Electronic Engineering in 2007, Masters in Communication Engineering in 2012 and a PhD in Communication Engineering in 2019. He is a member of many Engineering professional bodies. His research interests are in Wireless Sensor Networks and Smart Grids and has to his credit published works in the areas. 